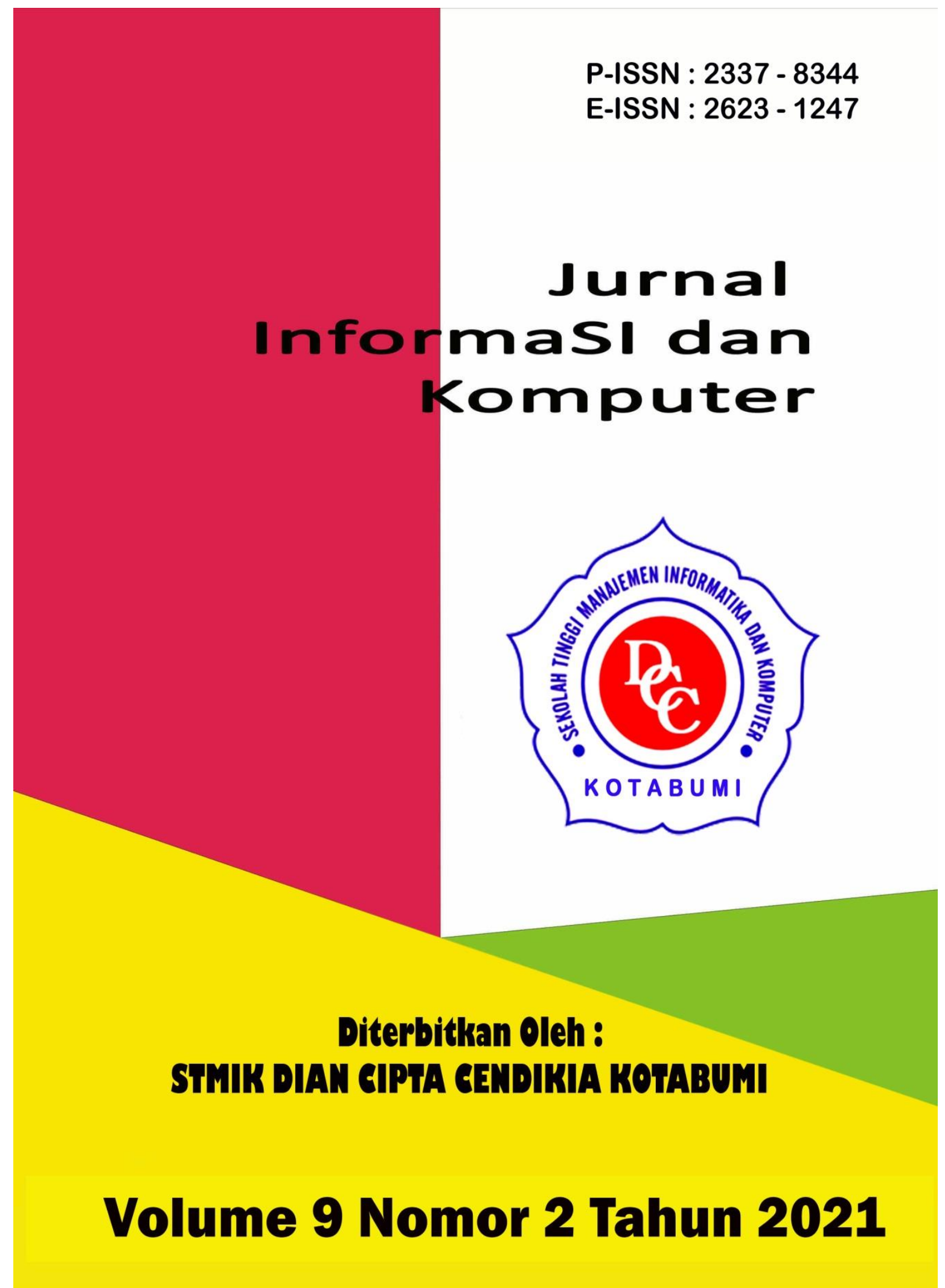




\section{Penerbit}

\section{Lembaga Penelitian STMIK Dian Cipta Cendikia Kotabumi}

Hak atas naskahh/tulisan tetap berada pada penulis, isi diluar tangung jawab penerbit dan Dewan Penyunting 


\section{PENGANTAR REDAKSI}

Puji syukur dipanjatkan kehadirat Tuhan Yang Maha Esa, atas karunia dan limpahan rahmatNYA jualah Jurnal Informasi dan komputer (JIK) STMIK Dian Cipta Cendikia Kotabumi ini dapat terwujud.Jurnal Informasi dan Komputer (JIK) yang terbit dua (2) kali dalam setahun ini merupakan suatu wadah untuk penyebar luasan hasil-hasil penelitian, studi pustaka, karya ilmiah yang berkaitan dengan Informasi dan Komputer khususnya bagi dosen-dosen STMIK Dian Cipta Cendikia Kotabumi serta umumnya para cendikiawan, praktisi, peneliti ilmu Informatika dan Komputer.

Harapan, dengan diterbitkannya Jurnal Informasi dan Komputer (JIK) ini sebagai salah satu bentuk sumbangan pemikiran dalam pengembangan ilmu informatika dan komputer yang berkaitan dengan kajian-kajian di bidang tekhnologi Informatik, Komunikasi Data dan Jaringan Komputer, perancangan dan Rekayasa Perangkat Lunak, serta ilmu-ilmu yang terkait dengan bidang Informasi dan Komputer lainnya.

Berkenaan dengan harapan tersebut, kepada para peneliti, dosen dan praktisi yang memiliki hasil-hasil penelitian, kajian pustaka, karya ilmiah dalam bidang tersebut diatas, dengan bangga redaksi Jurnal Informasi dan Komputer (JIK) menerima naskah ringkasan untuk dimuat pada jurnal Informasi dan Komputer (JIK) STMIK Dian Cipta Cendikia Kotabumi dengan berpedoman pada penulisan naskah jurnal sebagaimana dilampirkan pada halaman belakang (Bagian kulit dalam) buku jurnal ini.

Mutu dari suatu jurnal ilmiah tidak hanya ditentukan oleh para pengelolanya saja, tetapi para penulis dan pembaca jualah yang mempunyai peranan besar dalam meningkatkan mutu jurnal Informatika dan Komputer ini. Merujuk pada realita ini kamu sangat mengharapkan peran aktif dari peneliti untuk bersama-sama menjaga dan memelihara keberlangsungan dari jurnal Informasi dan Komputer STMIK Dian Cipta Cendikia Kotabumi ini. Yang juga tidak kalah pentingnya dari partisipasi tersebut diatas, adalah saran dan kritik yang membangun dari pembaca yang budiman agar kiranya dapat disampaikan langsung kepada redaksi JIK. Saran dan kritik yang membangun akan dijadikan masukan dan pertimbangan yang sangat berarti guna peningkatan mutu dan kualitas Jurnal Informasi dan Komputer STMIK Dian Cipta Cendikia Kotabumi.

Tak lupa diucapkan terima kasih yang tak terhingga atas perhatian dan kerjasama dari semua pihak yang tak dapat disebutkan satu persatu hingga dapat diterbitkan nya Jurnal Informasi dan Komputer (JIK) STMIK Dian Cipta Cendikia Kotabumi. Semoga apa yang telah diperbuat untuk kebaikan akan menjadi amal ibadah, amin.

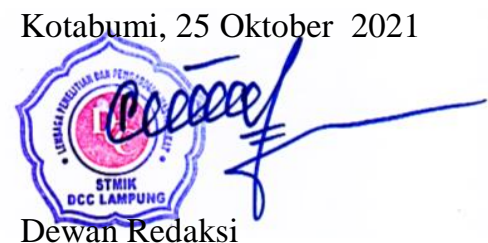




\section{JURNAL INFORMASI DAN KOMPUTER}

Volume 9 Nomor 2 Oktober 2021

Jurnal Informasi dan Komputer merupakan Sarana informasi ilmu pengetahuan, Tekhnologi dan Komunikasi yang berupa hasil penelitian, tulisan ilmiah, Ataupun studi pustaka. Jurnal ini terbit dua kali setahun pada bulan April dan Oktober. Berisi hasil penelitian ilmiah di bidang informatika yang bertujuan untuk menghubungkan adanya kesenjangan antar kemajuan teknologi dan hasil penelitian. Jurnal ini di terbitkan pertama kali pada tahun 2013.

Penanggung Jawab:

Ketua STMIK Dian Cipta Cendikia Kotabumi

\section{Pembina:}

Ketua STMIK Dian Cipta Cendikia Kotabumi Ketua Lembaga Penelitian STMIK Dian Cipta Cendikia Kotabumi

\section{Pimpinan Redaksi}

Dwi Marisa Efendi,.S.Kom.,M.Ti

\section{Redaksi pelaksana}

Rustam,.S.Kom,.M.Ti (STMIK Dian Cipta Cendikia Kotabumi)

Nurmayanti M.Kom (STMIK Dian Cipta Cendikia Kotabumi)

Sukatmi,.S.Kom., M.Kom (AMIK DCC Bandar Lampung)

Sampurna Dadi Riskiono,M.Kom (Universitas Teknokrat Indonesia)

Ifo Wahyu Pratama,S.Kom.,M.Ti(AMIK MASTER Lampung)

\section{Mitra Bestari}

Dr. RZ. ABDUL AZIZ, ST., MT (Institut Informatika dan Bisnis Darmajaya)

Dr. Dadang Sudrajat, S.Si, M.Kom (STMIK IKMI Cirebon)

Dr. Septafiansyah Dwi Putra, S.T., M.T (Politeknik Negeri Lampung)

Dr. Evi Grativiani, S.E., M.S.I (Universitas Sebelas Maret)

Rohmat Indra Borman ( Universitas Teknokrat Indonesia )

Ferry Wongso, S.KOm., M.Kom ( STMIK Darma Pala Riau)

Ferly Ardhy, S.Kom., M.Ti ( Universitas Aisyah Pringsewu )

Firmansyah, S.E., M.Si (STMIK Darma Pala Riau)
Amarudin (Universitas Teknokrat Indonesia)

Didi Susianto, S.T., M.Kom (AMIK Dian Cipta Cendika Bandar Lampung)

Alhibarsyah, St., M.Kom (STMIK Tunas

Bangsa Bandar Lampung)

Kemal Farouq Mauladi, S.Kom .M.Kom (Universitas Islam Lamongan)

Rima Mawarni, M.Kom ( STMIK Dian Cipta Cendikia Kotabumi)

Wira Jaya Hartono, S.Pd., M.Pd ( STMIK Darma Pala Riau)

Penerbit : STMIK Dian Cipta Cendikia Kotabumi Bekerja Sama Dengan LPPM STMIK Dian Cipta Cendikia Kotabumi.

\section{Alamat Redaksi/Penerbit:}

Jl. Negara No. 3 Candimas Kotabumi Lampung Utara

No Telpon/Fax 072423003

Email : 1ppm-stmik@dcc.ac.id 


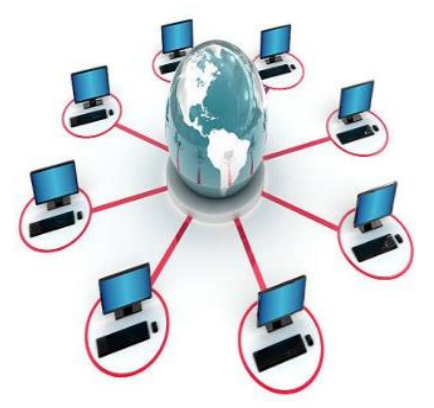

\section{JURNAL INFORMASI DAN KOMPUTER VOL. 9 NO. 2 THN. 2021}

\section{DAFTAR ISI}

Halaman

Sistem Informasi Akuntansi Persedian Barang Berbasis Web Pada Lembaga

Permasyarakatan Kelas II A Banceuy Bandung : "Kelompok Tani Desa Banjar Kertarahayu"

Teuku Rian Hardiyansyah, Fatia Salsa Azzahra

(Politeknik Piksi Ganesha Bandung ${ }^{1,2}$ ).

Penerapan Finite State Automata Pada Vending Machine Penjual Obat Non Resep

Dokter Dan Keperluan Medis

Eko Supriyanto $^{1}$, Angga Ardiansyah ${ }^{2}$, Frieyadie $^{3}$, Sri Rahayu ${ }^{4}$, Windu Gata ${ }^{5}$

(Universitas Nusa Mandiri ${ }^{12}$ )

Sistem Pendukung Keputusan Untuk Menentukan Kelayakan Pengajuan Sertifikasi Guru Dengan Metode Simple Additive Weighting (Studi Kasus : Ma Al Muhajirin Janti Jogoroto Jombang)

Budiman, umam baharudin, winarti

(Universitas Darul 'Ulum Jombang)

Perancangan Infrastruktur Domain Name Server Lokal Menggunakan Ubuntu Server 16.04

Pada PT. Xyz

Zaenal Mutaqin Subekti, Hendra Setiawan, Satria, Widia Murni Wijaya,

Aliy Hafiz, Warsudi

(STMIK Bani Saleh, Universitas Negeri Yogyakarta, AMIK Dian Cipta Cendikia,

STMIK MIC CIkarang)

Perancangan Sistem Informasi Idea Proposal (Ip) Berbasis Web Pada Pt. Paxel Algorita Unggul

Julian Murhan Sahputra, Indah Purnamasari

(Universitas Nusa Mandiri ${ }^{12}$ )

Sistem Pendukung Keputusan Untuk Menentukan Ekstrakurikuler Atletik

Berdasarkan Bakat Siswa Menggunakan Metode Profile Matching

Agnes Basuki, Petrus Sokibi, Tiara Eka Putri

(Universitas Catur Insan Cendekia)

Penerapan Algoritma K-Means Untuk Pengelompokan Usia Calon Penerima Vaksin

Di Kab. Ngawi

Irna Yuniarfi, Saifulloh

(Universitas PGRI Madiun ${ }^{12}$ )

System Penilaian Seleksi Calon Karyawan Baru Menggunakan Metode Simple Additive Weighting (SAW) Di PT.TNA

Anik Sri Wahyuningsih, Yudhi Firmansyah

(Universitas Panca Sakti Bekasi )

Perancangan Sistem Informasi Pembayaran SPP Menggunakan Framework Laravel 
Ichwan Habib Moudi

(Universitas Panca Sakti Bekasi) $75-80$

Implementasi Algoritma K-Means Dan Algoritma Apriori Optimasi Kinerja Ecu

(Study Kasus Mobil Avanza Dan Xenia)

Sigit Mintoro' Asep Afandi

(STMIK Dian Cipta Cendikia Kotabumi)

Sistem Pakar Penyakit Buah Kakao Untuk Peningkatan Hasil Panen Kakao Menggunakan

Metode Case Base Reasoning (CBR) Berbasis Web Mobile

Aliy hafiz, Verawati

(AMIK Dian Cipta Cendikia,Bandar Lampung)

Penerapan Metode Rapid Application Develomment (RAD) Dalam Pengembangan

Sistem Pemesanan Menu Berbasis Android

Aris Baihaqi, Tumini

(Fakultas Sains dan Teknologi ${ }^{1,2}$ )

Rancang Bangun Sistem Informasi Geografis Pariwisata Di Lampung Timur

Sukatmi, Rexa Alfa Rizi

(AMIK DCC Bandar Lampung ${ }^{12}$ )

Implementasi Psak No. 45 Pada Proses Penyusunan Laporan Keuangan Menggunakan

M.S. Excel Dan Aplikasi Accurate Accouting Pada STMIK Bani Saleh

Marhakim, Willy Adam

(STMIK Bani Saleh ${ }^{12}$ )

Sistem Prediksi Harga KOPI LAMBAR ( Lampung Barat) Dengan Metode

Backpropagation, dan Double Exponential ( Studi Kasus BUMDES )

Supriyanto, Dwi marisa Efendi,Rhomadhon

(STMIK Dian Cipta cendikia Kotabumi ${ }^{1-}$ )

Sistem Informasi Pemasaran Produk Umkm Berbasis Web Pada Kecamatan Bumi

Nabung Lampung Tengah

Yuli Syafitri, Agus Prasetyo, Reni Astika

(AMIK Dian Cipta Cendikia Bandar Lampung)

Rancang Bangun Aplikasi Pembelajaran Aksara Lampung Berbasis Android

Ferly Ardhy, Hendra Syahrobi

(Universitas Aisyah Pringewu ${ }^{1,}$ STMIK Dian Cipta Cendikia ${ }^{2}$ )

Sistem Pakar Diagnosa Penyakit Kulit Pada Balita Menggunakan Metode Naïve

Bayes Dan Forward Chaining Studi Kasus Puskesmas Cempaka Sungkai Selatan

Sidik Rahmatullah, Rima Mawarni

(STMIK Dian Cipta Cendikia Kotabumi ${ }^{12}$ )

Rekayasa Perangkat Lunak Perhitungan Harga Pokok Produksi Metode

Full Costing Pada Umkm Mitra Cake Di Bandar Lampung

Pitrawati, Arif Sanjaya

(AMIK Dian Cipta Cendikia, Bandar Lampung)

Rancang Bangun Sistem Ujian Online Menggunakan Algoritma Cosine Similarity

Berbasis Web

Haryono, Zaenal Mutaqin Subekti, Widiyawati, Hidayatullah

(STMIK Bani Saleh ${ }^{1234}$ ) 
Model Aplikasi Helpdesk Ticketing System Berbasis Web Menggunakan Metode Rad Indra Permana

Pattern Recognition Tulisan Tangan Huruf Hijaiyah Menggunakan Metode Convolutional Neural Network (CNN)

Mufassiril Abror, Nopiyanto

(Universitas Panca Sakti Bekasi ${ }^{12}$ )

Aplikasi Sistem Informasi Keuangan Berbasis Android Di Perumahan Taman

Karang Bahagia

Melda Ayulestari

(Universitas Panca Sakti Bekasi)

Audit Pelayanan Sistem Rujukan Online Puskesmas Menggunakan Framework COBIT 5.0

Nurmayanti, Merri Parida, Ngajiyanto, Ina Anzalna

(STMIK Dian Cipta Cendikia Kotabumi ${ }^{1234}$ )

Perancangan Sistem Informasi Pengolahan Data Nilai Siswa Berbasis Web

Erin Ermawati, Anik Sri Wahyuningsih

(Fakultas Sain dan Teknologi, Universitas Panca Sakti Bekasi ${ }^{12}$ )

Pengembangan Sistem Pelaporan Data Hasil Inspeksi Barang Berbasis Web

Siska Putriani

(Universitas Pancasakti Bekasi)

Penerapan Extreme Programming Dalam Perancangan Aplikasi Web Food Market

Tumini, Hilman Septiana

(Fakultas Sains dan Teknologi Universitas Panca Sakti Bekasi ${ }^{1,2}$ )

Sistem Pencarian Barang Berbasis Website Menggunakan Php Dan Mysql

Studi Kasus PT. Surya Technology Industri

Sulaeman

(Universitas Panca Sakti Bekasi)

Implementasi Metode Prototype Pada Sistem Peminjaman Alat Kerja Berbasis Web

Di PT SK Metalindo

Ali Mulyanto, Arjun Gunawan

(Univeritas Panca Sakti Bekasi)

Aplikasi Tata Cara Wudhu Menggunakan Teknologi Augmented Reality

Sebagai Media Pembelajaran

Di TK Al Fatih

Ahmad Yakub, Idarul Fadli

(Universitas Panca Sakti Bekasi ${ }^{12}$ )

Sistem Pakar Diagnosa Penyakit Ayam Petelur Menggunakan Metode Certainty Factor

Berbasis Web

Mochammad Taufiq Hidayat, Ali Mulyanto

(Universitas Panca Sakti Bekasi ${ }^{12}$ )

Penerapan Metode Prototyping Dalam Perhitungan Hasil Produksi Menggunakan

Arduino Uno R3 Dan Php Di PT. Indonesia Epson Industry

Amandha Aulia, Ajar Rohmanu

(Universitas Panca Sakti Bekasi ${ }^{12}$ ) 
System Pendukung Keputusan Penentuan Guru Teladan Dengan Metode Profile Matching

Hasbulloh, Agmawarnida

(Universitas Panca Sakti Bekasi ${ }^{1,2}$ )

Implementasi Waterfall Method Pada Aplikasi Buku Induk Siswa Berbasis Web

Idam Holid, Yogie Krisnayadi

(Universitas Panca Sakti ${ }^{12}$ )

Pengembangan Text To Speech Media Pembelajaran Untuk Pengenalan

Anggota Tubuh Manusia Kelas V Sekolah Dasar

Juwanda Saputra, Ali Mulianto

(Teknik Infomratika Fakulutas Sains dan Teknologi ${ }^{12}$ )

Perancangan Sistem Peminjaman Barang Berupa Aset Tetap Berbasis Web

Pada Lembaga Permasyarakatan Kelas II A Banceuy Bandung

Guntur Salasa Priambodo, Perwito, Candra Mecca Sufyana

(Politeknik Piksi Ganesha Bandung ${ }^{1,2,3}$ )

Metode Pemilihan Karyawan Terbaik Sebagai Penentu Goodwill Perguruan Tinggi

Dengan Menggunakan Metode Topsis (Studi Kasus Perguruan Tinggi Di Lampung Utara)

Dwi Sartika, Pakarti Riswanto

(STMIK Dian Cipta Cendikia Kotabumi)

Sistem Pendukung Keputusan Pemilihan Merek Smartphone Menggunakan

Metode Analytical Hierarchy Process (AHP)

Ade Kiki Fatmawati, Muhammad Sultan Raflie, Norma Yunita

(Universitas Nusa Mandiri ${ }^{123}$ )

Pattern Recognition Aksara Lampung Menggunakan Algoritma Neural Network

Metode Analytical Hierarchy Process (AHP)

Nopiyanto, Rahmadi

(Universitas Panca Sakti Bekasi) 116-121 


\title{
AUDIT PELAYANAN SISTEM RUJUKAN ONLINE PUSKESMAS MENGGUNAKAN FRAMEWORK COBIT 5.0
}

\author{
Nurmayanti ${ }^{1}$, Merri Parida ${ }^{2}$, Ngajiyanto ${ }^{3}$, Ina Anzalna ${ }^{4}$ \\ STMIK Dian Cipta Cendikia Kotabumi ${ }^{1234}$ \\ Jl. Negara Nomor 03. Candimas Kotabumi Lampung Utara ${ }^{1234}$ \\ Email : nurma@dcc.ac.id ${ }^{1}$, Merri@dcc.ac.id ${ }^{2}$,ngajiyanto@dcc.ac.id ${ }^{3}$, Inaanzalna49@gmail.com ${ }^{4}$
}

\begin{abstract}
ABSTRAK
Rujukan online merupakan sistem yang menjembatani antara Fasilitas Kesehatan Tingkat Pertama (FKTP) dengan rumah sakit sebagai Faskes penerima rujukan. Tujuannya untuk kemudahan dan kepastian peserta dalam memperoleh layanan di rumah sakit. Layanan disesuaikan dengan kompetensi, jarak dan kapasitas rumah sakit tujuan rujukan berdasarkan kebutuhan medis pasien. Metode yang dilakukan pada penelitian ini menggunakan kerangka kerja COBIT 5.0. Dengan 5 domain proses yaitu DSS02, DSS03, MEA01, MEA02, dan EDM02 yang bertujuan untuk meningkatkan proses kapabilitas agar mencapai tingkat kapabilitas yang diharapkan. Hasil dari penelitian ini yaitu menghasilkan nilai ratarata dari kelima domain adalah 3.23 berada pada level 3 (Established Process) dari target yang diinginkan 4, kesenjangan/gap dengan nilai 0.77 yang artinya Pelayanan Sistem Rujukan Online Puskesmas sudah baik dan mendekati nilai yang diharapkan.
\end{abstract}

Kata Kunci : Audit, Pelayanan Sistem Rujukan Online Puskesmas, COBIT 5.0

\section{ABSTRACT}

Online referral is a system that bridges the First Level Health Facility (FKTP) and the hospital as the health facility that receives the referral. The goal is for the convenience and certainty of participants in obtaining services at the hospital. Services are tailored to the competence, distance and capacity of the referral hospital based on the patient's medical needs. The method used in this study uses the COBIT 5.0 framework. With 5 process domains namely DSSO2, DSSO3, MEAO1, MEAO2, and EDMO2 which aims to improve the process capability in order to achieve the expected level of capability. The results of this study are that the average value of the five domains is 3.23, which is at level 3 (Established Process) from the desired target 4 , the gap with a value of 0.77 which means that the Puskesmas Online Referral System Service is good and close to the expected value.

Keywords: Audit, Health Center Online Referral System Service, COBIT 5.0

\section{PENDAhUluAN}

\subsection{Latar Belakang}

Perkembangan teknologi informasi dan sistem informasi saat ini sangat cepat, karena kemudahan dalam memperoleh informasi dalam mengembangkan teknologi. Bahkan hampir di semua bidang-bidang dan lingkup pekerjaan sudah dapat menggunakan kemajuan teknologi, khususnya dalam bidang kesehatan pada pelayanan pasien yang sudah layaknya menggunakan teknologi informasi dan sistem informasi untuk meningkatkan pelayanan pasien pada sarana pelayanan kesehatan. Salah satunya, memanfaatkan teknologi informasi (TI) untuk menjadikan sistem informasi yang terintegrasi dan dapat diakses secara langsung oleh user, sehingga dengan adanya sistem informasi tersebut pengerjaan operasional bisa terbantu.

Puskesmas merupakan salah satu instansi kesehatan yang sudah berkembang menggunakan sistem informasi. Puskesmas telah menerapkan TI sebagai infrastruktur untuk memberikan pelayanan rujukan online yang ditampung dalam aplikasi primary care bpjs kesehatan di laman pcare.bpjskesehatan.go.id. Primary Care adalah aplikasi 
yang digunakan oleh petugas atau dokter fasilitas kesehatan tingkat pertama seperti puskesmas dan klinik untuk pengecekan data peserta yang mendaftar di sana. Di aplikasi ini juga, petugas akan mengisi riwayat pengobatan dari seluruh pendaftar. Akan tetapi pelayanan dan pengolahan registrasi pasien di instansi ini, ada beberapa yang masih mempunyai kendala yaitu belum optimalnya proses kerja pelayanan sistem rujukan online sehingga waktu menjadi kurang efektif, dan terjadi ketidaknyamanan pada

pasien yang meminta rujukan. Untuk itu perlu dilakukannya audit teknologi informasi. Dengan dilakukannya audit maka dapat diketahui tingkat pelayanan yang telah dilakukan sehingga mendorong pencapaian tujuan secara efektif dan juga dapat diketahui tingkat kematangan teknologi informasi serta menghasilkan rekomendasi untuk mencapai tingkat kematangan yang optimal. Audit teknologi informasi memiliki beberapa standar yang digunakan untuk peneletian. Contoh standar tersebut adalah COBIT 5.

\section{LANDASAN TERORI}

\subsection{Audit}

Menurut Sukrisno Agoes (2014), “Audit adalah suatu pemeriksaan yang dilakukan secara kritis dan sistematis oleh pihak yang independen, terhadap laporan keuangan yang telah disusun oleh manajemen beserta catatan-catatan pembukuan dan buktibukti pendukungnya, dengan tujuan untuk dapat memberikan pendapat tentang kesesuain laporan keuangan tersebut"

\subsection{Sistem}

Menurut Romney (2015), Sistem adalah serangkaian dua atau lebih komponen yang saling terkait dan berinteraksi untuk mencapai suatu tujuan.

Menurut Indrajani (2015), Sistem didefinisikan sebagai sekelompok elemen yang saling berhubungan atau berinteraksi hingga membentuk satu persatuan. Konsep umum system adalah sekelompok komponen yang saling berhubungan, bekerja sama untuk mencapai tujuan bersama dengan menerima input serta menghasilkan output dalam proses transformasi yang teratur. Selain itu juga,
COBIT 5 merupakan standar komprehensif yang membantu organisasi dalam mencapai tujuan dan menghasilkan nilai melalui tata kelola dan manajemen teknologi informasi yang efektif. COBIT 5 menyediakan kerangka kerja yang lengkap, terdapat 5 domain dan 37 proses pada COBIT 5 yang dapat digunakan untuk melakukan audit. Maka dari itu COBIT 5 dianggap sesuai dan dapat membantu dalam proses audit teknologi informasi karena mencakup semua elemen pada teknologi informasi yang dipakai. Domain DSS02, DSS03, MEA01, MEA02 dan

EDM02 dipilih karena dianggap sesuai dengan kondisi teknologi informasi yang ada pada pelayanan system rujukan online puskesmas saat ini.

Berdasarkan uraian yang telah dijelaskan, maka penulis bermaksud untuk mengangkat permasalahan tersebut sebagai bahan penelitian. Adapun judul yang penulis pilih adalah "Audit Pelayanan Sistem Rujukan Online Puskesmas Menggunakan Framework COBIT 5.0".

sistem adalah elemen-elemen yang terintegrasi dengan maksud untuk mencapai tujuan organisasi atau perusahaan yang terdiri atas sejumlah sumber daya. Sumber daya tersebut bekerja menuju tercapainya suatu tujuan tertentu yang ditentukan oleh pemilik atau manajemen perusahaan tersebut.

\subsection{Informasi}

Menurut Yuliana, dkk (2018), "Secara umum, informasi dapat didefinisikan sebagai hasil pengolahan data dalam suatu bentuk yang lebih berguna dan lebih berarti bagi penerimanya yang menggambarkan kejadian-kejadian yang nyata yang digunakan untuk pengambilan keputusan".

Menurut I Putu Agus Eka Pratama (2014) "Informasi merupakan hasil pengolahan data dari satu atau berbagai sumber, yang kemudian diolah, sehingga memberikan nilai, arti dan manfaat. Pada proses pengolahan data, untuk dapat menghasilkan informasi, juga dilakukan proses verifikasi secara akurat, spesifik dan tepat waktu. Hal ini penting agar informasi dapat memberikan nilai dan pemahaman kepada pengguna. Pengguna dalam hal ini mencakup pembaca, pendengar, penonton, 
bergantung pada bagaimana cara pengguna tersebut menikmati sajian informasi dan melalui media apa informasi tersebut disajikan".

\subsection{Sistem Informasi}

Menurut Kadir (2014), Sistem informasi adalah "Sebuah rangkaian prosedur formal dimana data dikelompokkan, diproses menjadi informasi, dan didistribusikan kepada pemakai”.

Menurut Krismaji (2015), "Sistem informasi adalah cara-cara yang diorganisasi untuk mengumpulkan, memasukkan, dan mengolah serta menyimpan data, dan cara-cara yang diorganisasi untuk menyimpan, mengelola, mengendalikan, dan melaporkan informasi sedemikian rupa sehingga sebuah organisasi dapat mencapai tujuan yang telah ditetapkan".

\subsection{Audit Sistem Informasi}

Menurut Gondodiyoto (2013), “Audit sistem informasi merupakan suatu pengevaluasian untuk mengetahui bagaimana tingkat kesesuaian antara aplikasi sistem informasi dengan prosedur yang telah ditetapkan dan mengetahui apakah suatu sistem informasi telah didesain dan diimplementasikan secara efektif, efisien, dan ekonomis, memiliki mekanisme pengamanan aset yang memadai, serta menjamin integritas data yang memadai”.

Menurut Candra, dkk (2015), "Audit sistem informasi adalah proses pengumpulan bukti dan evaluasi untuk mengetahui tingkat kesesuaian sistem informasi dengan prosedur yang telah ditetapkan dan mengetahui apakah sistem informasi telah didesain dan diimplementasikan secara efektif, efisien dan ekonimis, memiliki mekanisme pengamanan asset yang memadai dan menjamin integritas data".

\subsection{Rujukan Online}

Rujukan online merupakan sistem yang menjembatani antara Fasilitas Kesehatan Tingkat Pertama (FKTP) dengan rumah sakit sebagai Faskes penerima rujukan.“

Sistem rujukan online ini mendukung sistem rujukan berjenjang, FKTP dapat merujuk ke Fasilitas Kesehatan Rujukan Tingkat Lanjutan
(FKRTL) terdekat dengan tetap mempertimbangkan kompetensi dokter, sarana/prasarana dan kapasitas rumah sakit sesuai kebutuhan medis.

\subsection{Control Objective for Information \& Related Technology (COBIT 5)}

Menurut Sasongko (2009), "Control Objective for Information \& Related Technology

(COBIT) adalah sekumpulan dokumentasi best practice untuk IT Governance yang dapat membantu auditor, pengguna (user), dan manajemen, untuk menjembatani gap antara resiko bisnis, kebutuhan kontrol dan masalahmasalah teknis IT".

\section{Prinsip COBIT}

COBIT memungkinkan teknologi informasi melakukan tata kelola dan manajemen secara holistik untuk keseluruhan enterprise, mengelola bisnis dari ujung ke ujung, bertanggung jawab pada keseluruhan area fungsi teknologi informasi. Selain itu juga dalam COBIT 5 menyediakan fasilitas dalam cakupan stakeholder internal dan eksternal. COBIT 5 bersikap global dan bermanfat untuk semua enterprise dengan berbagai skala, baik komersial, non profit, maupun sektor publik. COBIT 5 mempunyai lima prinsip (ISACA, 2012):

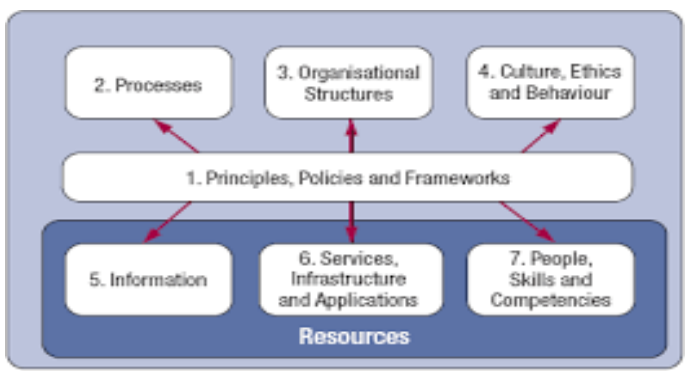

Gambar 1. Prinsip COBIT 5 (ISACA, 2012)

COBIT 5 berdasarkan lima prinsip kunci pada gambar 1 untuk tata kelola dan manajemen TI (ISACA, 2012) adalah :

1. Prinsip $1:$ Menemukan kebutuhan

2. Prinsip 2 : Mencakup ujung ke ujung enterprise 
3. Prinsip 3 : Mengaplikasikan yang tunggal, mengintegrasikan framework

4. Prinsip 4 : Mengaktifkan pendekatan holistic

5. Prinsip 5 : Memisahkan tata kelola dengan manajemen

\section{COBIT 5 Process Reference Model}

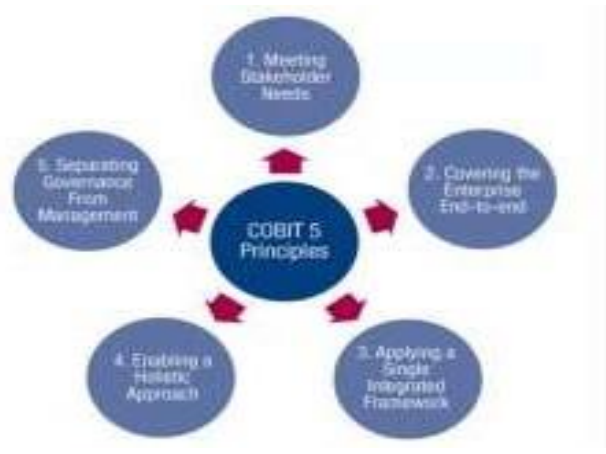

Gambar 2. Area Kunci Tata Kelola dan Manajemen COBIT 5 (ISACA, 2012)

Proses pada COBIT 5 terdiri dari dua proses yaitu proses tata kelola dan proses manajemen.

1. Tata kelola: berisi lima proses tata kelola; yang masing-masing proses dievaluasi, diarahkan, dimonitor (EDM).

2 EDM01 Memastikan terdapat pengaturan dan pemeliharaan kerangka kerja tata kelola (Ensure governance framework setting and maintenance).

3. EDM02 Memastikan mendapat keuntungan/manfaat (Ensure benefits delivery.

4. EDM03 Memastikan optimalisasi resiko (Ensure risk optimisation).

5. EDM04 Memastikan optimalisasi sumber daya (Ensure resource optimisation).

6. EDM05 Memastikan transparasi terhadap stakeholder (Ensure stakeholder transparancy).

Manajemen (Management) Terdapat empat domain proses yang sejajar dengan area tanggung jawab dari Plan, Build, Run, and Monitor (PBRM) serta menyediakan ruang lingkup TI yang menyeluruh terdiri dari:

Domain Meluruskan, Merencanakan dan Mengatur (Align, Plan and Organise) yang memuat 13 proses, yaitu: a. APO01 Mengelola manajemen kerangka kerja TI (Manage the IT management framework).

b. APO02 Mengelola strategi (Manage strategy).

c. APO03 Mengelola arsitektur informasi (Manage enterprise architecture)

d. APO04 Mengelola inovasi/perubahan (Manage innovation).

e. APO05 Mengelola portofolio (Manage portofolio).

f. APO06 Mengelola anggaran dan biaya (Manage budget and costs).

g. APO07 Mengelola sumber daya manusia (Manage human resource).

h. APO08 Mengelola hubungan (Manage relationships).

i. APO09 Mengelola perjanjian layanan (Manage service agreements).

j. APO10 Mengelola pemasok/supplier (Manage suppliers).

k. APO11 Mengelola kualitas (Manage quality).

1. APO12 Mengelola resiko (Manage risk).

m. APO13 Mengelola keamanan (Manage security)

Domain Membangun, Memperoleh dan Mengoperasikan (Build, Acquire and Operate) memuat 10 proses, yaitu:

1. BAI01 Mengelola program dan proyek (Manage programmes and projects)

2. BAI02 Mengelola definisi kebutuhan (Manage requirements definitions).

3. BAI03 Mendefinisikan solusi otomatis (Manage solutions identification and build).

4. BAI04 Mengelola ketersediaan dan kapasitas (Manage availability and capacity).

5. BAI05 Mengelola perubahan pemberdayaan organisasi (Manage organizational change enablement).

6. BAI06 Mengelola perubahan (Manage changes).

7. BAI07 Mengelola penerimaan perubahan dan transisi (Manage change acceptance and transitioning).

8. BAI08 Mengelola pengetahuan (Manage knowledge). 
9. BAI09 Mengelola aset (Manage assets).

10. BAI10 Mengelola susunan (Manage configuration).

Domain Menghasilkan, Melayani, dan Mendukung (Deliver, Service and Support) memuat 7 proses, yaitu:

1. DSS01 Mengelola operasi (Manage operations).

2. DSS02 Mengelola permintaan layanan (Managed Outsourced Services). DSS03 Mengelola permasalahan (Manage problems).

3. DSS04 Mengelola layanan yang berkelanjutan (Manage continuity).

4. DSS05 Mengelola layanan keamanan (Manage security service).

5. DSS06 Mengelola proses bisnis (Manage business process controls).

6. Domain Mengawasi, Mengevaluasi, Menilai (Monitor, Evaluate, Assess) memuat 3 proses, yaitu:

7. MEA01 Mengawasi, mengevaluasi, menilai kinerja dan kesesuaian (Monitor, evaluate and assess performance and conformance). MEA02 Mengawasi, mengevaluasi, menilai sistem pengendalian internal (Monitor, evaluate and assess the system of internal control). MEA03 Mengawasi, mengevaluasi, menilai kepatuhan dan kebutuhan eksternal (Monitor, evaluate and assess compliance with external requirements).

\subsubsection{Proses Capability Model}

ISO/IEC mendefinisikan pengukuran untuk penilaian kemampuan proses dari framework COBIT. Process capability didefinisikan pada 6 level poin dari 0 sampai 5, yang mempresentasikan peningkatan capability dari proses yang diimplementasikan. Berikut adalah penjelasan level dari process capability :

\section{Tabel Capability Level}

Tabel 2. Level Capability

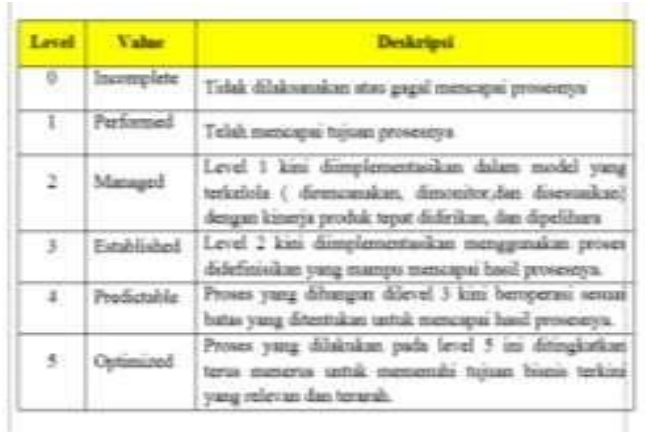

\section{METODE PENELITIAN}

\subsection{Visi Puskesmas}

Visi pembangunan kesehatan yang diselenggarakan oleh Puskesmas adalah tercapainya Kecamatan Sehat menuju terwujudnya Indonesia Sehat Indikator Kecamatan Sehat:

1. lingkungan sehat,

2. perilaku sehat,

3. cakupan pelayanan kesehatan yang bermutu derajat kesehatan penduduk kecamatan

\subsection{Misi Puskesmas}

1. Menggerakkan pembangunan berwawasan kesehatan di wilayah kerjanya

2. Mendorong kemandirian hidup sehat bagi keluarga dan masyarakat di wilayah kerjanya

3. Memelihara dan meningkatkan mutu, pemerataan dan keterjangkauan pelayanan kesehatan yang diselenggarakan

4. Memelihara dan meningkatkan kesehatan perorangan, keluarga dan masyarakat beserta lingkungannya

\subsection{Jenis Penelitian}

Penelitian kuantitatif adalah metode penelitian yang berlandaskan pada filsafat positivisme, digunakan untuk meneliti pada populasi atau sampel tertentu, teknik pengambilan sampel pada umumnya dilakukan secara random, pengumpulan data menggunakan instrument penelitian, analisis data bersifat kuantitatif/statistic dengan tujuan untuk menguji hipotesis yang telah ditetapkan. 


\subsection{Teknik Pengumpulan Data}

Dalam suatu penelitian selalu terjadi proses pengumpulan data yang harus disesuaikan dengan sifat dan karakteristik penelitian yang dilakukan sehingga diperlukan metode pengumpulan yang tepat untuk memperoleh data yang dibutuhkan. Oleh karena itu, untuk memperoleh data dimaksud peneliti menggunakan beberapa metode pengumpulan data sebagai berikut :

Metode wawancara (interview) interview atau wawancara merupakan metode pengumpulan data yang menghendaki komunikasi langsung antara peneliti dengan subyek atau responden. Dalam hal ini peneliti melakukan tanya jawab secara langsung dengan staff layanan rujukan puskesmas untuk mendapatkan gambaran umum tentang Pelayanan Rujukan Online.

\section{Metode Observasi}

Observasi (pengamatan) adalah alat pengumpulan data yang dilakukan dengan cara mengamati dan mencatat secara sitematik gejala-gejala yang diselidiki. Dalam metode ini dilakukan penelitian secara langsung dalam memperoleh data dari lapangan.

\section{Studi Literalur}

Pada bagian ini akan difokuskan pada pencarian referensi relevan yang berkaitan dengan permasalahan yang sedang di teliti oleh penulis. Hal ini dilakukan agar peneliti mampu meningkatkan pemahaman dan pengetahuan teori tentang permasalahan yang sedang diteliti.

\section{Kuisoner}

Pada bagian ini akan difokuskan pada pencarian referensi relevan yang berkaitan dengan permasalahan yang sedang di teliti oleh penulis. Hal ini dilakukan agar peneliti mampu meningkatkan pemahaman dan pengetahuan teori tentang permasalahan yang sedang diteliti.

\subsection{Teknik Analisis Data}

Penelitian yang diteliti menggunakan sejumlah sampel yang mewakili populasi Pengguna system rujukan online pada puskesmas. Pada pengukuran data, penulis melakukan beberapa tahap sebagai berikut :

\section{Skala Likert}

Skala likert ini digunakan untuk mengukur pendapat sikap, pendapat dan persepsi seseorang atau sekelompok orang dalam mengamati atau memberikan penilai terhadap fenomena social dalam penilaian tingkat pelayanan rujukan online, dibuatlah 5 Skala likert sebagai berikut:

Tabel 9. Skala likert

\begin{tabular}{|c|l|}
\hline \multicolumn{1}{|l|}{ Skala } & \multicolumn{1}{c|}{ Keterangan } \\
\hline 1 & Sangat Tidak Setuju \\
\hline 2 & Tidak Setuju \\
\hline 3 & Ragu-ragu ( Netral ) \\
\hline 4 & Setuju \\
\hline 5 & Sangat Setuju \\
\hline
\end{tabular}

\section{Analisis Kesenjangan}

Analisis kesenjangan digunakan untuk mengetahui kesenjangan (gap) antara hasil survei berupa nilai aktual dengan nilai ekspektasi yang telah ditentukan. Kemudian akan dianalisis penyebab terjadinya kesenjangan tersebut.

Gap = Nilai Aktual - Nilai Ekspektasi

\section{Pelaporan (Reporting)}

Setelah kuesioner disebarkan, maka akan didapat data yang akan diproses untuk dihitung berdasarkan perhitungan maturity level. Untuk selanjutnya dilakukan beberapa tahapan dalam pelaporan yaitu :

4. Hasil audit berisi temuan sekarang (Capability Level) dan harapan pada masa yang akan datang (Target)

5. Analysis gap dilakukan cara mencari Gap Analysis Capability Level.

6. Rekomendasi berisi tindakan korektif mengatasi gap yang dilakukan untuk mencapai perbaikan yang dilakukan untuk institusi tersebut.

7. Tindakan ini bagaimana menghasilkan nilai sistem informasi yang optimal. 


\section{HASIL DAN PEMBAHASAN}

\section{Hasil Penelitian}

\section{Data Keseluruhan Berdasarkan Usia}

Responden

Dari data responden untuk audit pelayanan sistem rujukan online puskesmas pada framework DSS02, DSS03, MEA01, MEA02, dan EDM02, ada beberapa kategori kelas usia responden yang dapat dilihat pada tabel berikut

\section{Data Keseluruhan Responden Berdasarkan Jenis Kelamin}

Dari data responden untuk audit sistem pelayanan rujukan online pada framework DSS02, DSS03, MEA01, MEA02, dan EDM02 ada beberapa kategori jenis kelamin responden yang dapat dilihat pada tabel berikut :

Tabel 12. Responden Berdasarkan Jenis Kelamin

\begin{tabular}{|c|c|c|}
\hline Jenis Kelamin & Jumlah & $\begin{array}{c}\text { Persentas } \\
\mathrm{e}\end{array}$ \\
\hline $\mathrm{L}$ & 58 & $39 \%$ \\
\hline $\mathrm{P}$ & 92 & $61 \%$ \\
\hline total & 150 & $100 \%$ \\
\hline
\end{tabular}

Tabel 13. Bobot pernyataan

\begin{tabular}{|c|l|c|}
\hline No. & Bobot Pernyataan & Bobot \\
\hline 1 & Sangat Tidak Setuju & 1 \\
\hline 2 & Tidak Setuju & 2 \\
\hline 3 & Ragu-ragu ( Netral ) & 3 \\
\hline 4 & Setuju & 4 \\
\hline 5 & Sangat Setuju & 5 \\
\hline
\end{tabular}

Pada masing-masing pertanyaan dihitung nilai rata-rata konversinya dengan rumus:

$$
\text { Nilai Rata }- \text { Rata }=\frac{\text { Nilai Konversi }}{\sum \text { Jumlah Responden }}
$$

\section{- Proses Capability Domain DSS02}

Dari hasil pengisian kuesioner pertanyaan pada framework DSS02 didapatkan indeks Capability yang dapat dilihat pada tabel berikut :

Tabel 35. Capabiliity Level Domain DSS02

\begin{tabular}{|r|c|c|c|}
\hline Sub Domain & Level & Target & Gap \\
\hline DSS02.01 & 3,28 & 4 & 0,72 \\
\hline DSS02.02 & 2,99 & 4 & 1,01 \\
\hline DSS02.03 & 2,90 & 4 & 1,1 \\
\hline
\end{tabular}

\begin{tabular}{|l|c|c|c|}
\hline $\begin{array}{l}\text { DSS02.0 } \\
4\end{array}$ & 3,11 & 4 & $\begin{array}{c}0, \\
89\end{array}$ \\
\hline $\begin{array}{l}\text { Rata- } \\
\text { Rata }\end{array}$ & $\mathbf{3 . 0 7}$ & $\mathbf{4}$ & $\mathbf{0 .}$ \\
$\mathbf{9}$
\end{tabular}

Dari semua perhitungan kuesioner di dapat nilai rata-rata 3.07 (Established Process) untuk Domain DSS02, jadi dapat disimpulkan bahwa Audit Pelayanan Sistem Rujukan Online Puskesmas pada tahap ini memiliki prosesproses TI yang sudah distandarkan dalam ruang lingkup Pelayanan Sistem Rujukan Online Puskesmas secara keseluruhan.

\section{- Proses Capability Domain DSS03}

Dari hasil pengisian kuesioner pertanyaan pada framework DSS03 didapatkan indeks Capability yang dapat dilihat pada tabel berikut

Tabel 36. Capabiliity Level Domain DSS03

\begin{tabular}{|l|c|c|c|}
\hline $\begin{array}{l}\text { Sub } \\
\text { Domain }\end{array}$ & $\begin{array}{c}\text { Leve } \\
\text { I }\end{array}$ & Target & Gap \\
\hline DSS03.01 & 2.94 & 4 & 1.06 \\
\hline DSS03.02 & 2.82 & 4 & 1.18 \\
\hline DSS03.03 & 3.06 & 4 & 0.94 \\
\hline DSS03.04 & 2.99 & 4 & 1.01 \\
\hline $\begin{array}{l}\text { Rata- } \\
\text { Rata }\end{array}$ & $\mathbf{2 . 9 5}$ & $\mathbf{4}$ & $\mathbf{1 . 0 5}$ \\
\hline
\end{tabular}

Dari semua perhitungan kuesioner di dapat nilai rata-rata 2.95 (Established Process) untuk Domain DSS03, jadi dapat disimpulkan bahwa Audit Pelayanan Sistem Rujukan Online Puskesmas pada tahap ini memiliki prosesproses TI yang sudah distandarkan dalam ruang lingkup Pelayanan Sistem Rujukan Online 
Puskesmas secara keseluruhan.

\section{Proses Capability Domain MEA01}

Dari hasil pengisian kuesioner pertanyaan pada framework MEA01 didapatkan indeks Capability yang dapat dilihat pada tabel berikut :

\begin{tabular}{|l|c|c|c|}
\hline $\begin{array}{l}\text { Sub } \\
\text { Domain }\end{array}$ & Level & $\begin{array}{c}\text { Targ } \\
\text { et }\end{array}$ & Gap \\
\hline EDM02.01 & 3,63 & 4 & 0,37 \\
\hline EDM02.02 & 3, & 4 & 0,2 \\
\hline EDM02.03 & 3,34 & 4 & 0,66 \\
\hline EDM02.04 & 3,18 & 4 & 0,82 \\
\hline Rata-Rata & $\mathbf{3 , 4 8}$ & $\mathbf{4}$ & $\mathbf{0 , 5 2}$ \\
\hline
\end{tabular}

Tabel 37. Capabiliity Level Domain MEA01

\begin{tabular}{|l|c|c|c|}
\hline $\begin{array}{l}\text { Sub } \\
\text { Domain }\end{array}$ & Level & Target & Gap \\
\hline MEA01.01 & 3,54 & 4 & 0,46 \\
\hline MEA01.02 & 2,94 & 4 & 1,06 \\
\hline MEA01.03 & 3,57 & 4 & 0,43 \\
\hline MEA01.04 & 3,45 & 4 & 0,55 \\
\hline Rata-Rata & $\mathbf{3 , 3 7}$ & $\mathbf{4}$ & $\mathbf{0 , 6 3}$ \\
\hline
\end{tabular}

Dari semua perhitungan kuesioner di dapat nilai rata-rata 3,37 (Established Process) untuk Domain MEA01, jadi dapat disimpulkan bahwa Audit Pelayanan Sistem Rujukan Online Puskesmas pada tahap ini memiliki prosesproses TI yang sudah distandarkan dalam ruang lingkup Pelayanan Sistem Rujukan Online Puskesmas secara keseluruhan.

\section{- Proses Capability Domain MEA02}

Dari hasil pengisian kuesioner pertanyaan pada framework MEA02 didapatkan indeks Capability yang dapat dilihat pada tabel berikut :

Tabel 38. Capabiliity Level Domain MEA02

\begin{tabular}{|l|c|c|c|}
\hline $\begin{array}{l}\text { Sub } \\
\text { Domain }\end{array}$ & Level & Target & Gap \\
\hline MEA02.01 & 3,48 & 4 & 0,52 \\
\hline MEA02.02 & 3,20 & 4 & 0,8 \\
\hline
\end{tabular}

\begin{tabular}{|l|l|l|l|}
\hline MEA02.03 & 3,26 & 4 & 0,74 \\
\hline MEA02.04 & 3,24 & 4 & 0,76 \\
\hline Rata-Rata & $\mathbf{3 , 2 9}$ & $\mathbf{4}$ & $\mathbf{0 , 7 1}$ \\
\hline
\end{tabular}

Dari semua perhitungan kuesioner di dapat nilai rata-rata 3,29 (Established Process) untuk Domain MEA02, jadi dapat disimpulkan bahwa Audit Pelayanan Sistem Rujukan Online

Puskesmas pada tahap ini memiliki prosesproses TI yang sudah distandarkan dalam ruang lingkup Pelayanan Sistem Rujukan Online Puskesmas secara keseluruhan.

\section{- Proses Capability Domain EDM02}

Dari hasil pengisian kuesioner pertanyaan pada framework EDM02 didapatkan indeks Capability yang dapat dilihat pada tabel berikut

\section{Tabel 39. Capabiliity Level Domain EDM02}

target yang ingin dicapai. Berdasarkan hasil proses penilaian terhadap proses DSS02, DSS03, MEA01, MEA02 dan

EDM02 maka dapat dirangkum ke dalam tabel berikut:

\begin{tabular}{|c|c|c|c|c|}
\hline \multirow[t]{2}{*}{$\begin{array}{l}\text { ID } \\
\text { Pro } \\
\text { ses }\end{array}$} & \multirow[t]{2}{*}{ Nama Proses } & $\begin{array}{c}\text { Leve I } \\
\text { Saat } \\
\text { Ini }\end{array}$ & $\begin{array}{c}\text { Level } \\
\text { Targe t }\end{array}$ & $\begin{array}{c}\mathbf{G a} \\
\mathbf{p}\end{array}$ \\
\hline & & $\mathbf{X}$ & $\mathbf{Y}$ & $\begin{array}{l}Y- \\
X\end{array}$ \\
\hline $\begin{array}{l}\text { DS } \\
\text { S02 }\end{array}$ & $\begin{array}{l}\text { Managed } \\
\text { Outsourced } \\
\text { Services }\end{array}$ & 3.07 & 4 & $\begin{array}{c}0.9 \\
3\end{array}$ \\
\hline $\begin{array}{l}\text { DS } \\
\text { S03 }\end{array}$ & Manage Problems & 2.95 & 4 & $\begin{array}{c}1.0 \\
5\end{array}$ \\
\hline $\begin{array}{l}\text { ME } \\
\text { A01 }\end{array}$ & $\begin{array}{l}\text { Monitor, evaluate } \\
\text { and assess } \\
\text { performance and } \\
\text { conformance }\end{array}$ & 3.37 & 4 & $\begin{array}{c}0.6 \\
3\end{array}$ \\
\hline $\begin{array}{l}\mathrm{ME} \\
\mathrm{A} 02\end{array}$ & $\begin{array}{l}\text { Monitor, } \\
\text { evaluate and } \\
\text { assess the system } \\
\text { of internal } \\
\text { control }\end{array}$ & 3.29 & 4 & $\begin{array}{c}0.7 \\
1\end{array}$ \\
\hline $\begin{array}{l}\text { ED } \\
\text { M0 } \\
2\end{array}$ & $\begin{array}{l}\text { Ensure benefits } \\
\text { Delivery }\end{array}$ & 3.48 & 4 & $\begin{array}{c}0.5 \\
2\end{array}$ \\
\hline Rat & & 3.23 & 4 & $\begin{array}{c}0,7 \\
7\end{array}$ \\
\hline
\end{tabular}

Tabel 40. Analisa GAP

Dari semua perhitungan kuesioner di dapat nilai 
rata-rata 3,48 (Established Process) untuk Domain EDM02, jadi dapat disimpulkan bahwa Audit Pelayanan Sistem Rujukan Online Puskesmas pada tahap ini memiliki prosesproses TI yang sudah distandarkan dalam ruang lingkup Pelayanan Sistem Rujukan Online Puskesmas secara keseluruhan.

\section{- Analisis Gap}

Analisis kesenjangan dilakukan untuk mengetahui kesenjangan atau perbedaan yang terjadi antara kondisi saat ini dengan kondisi yang diharapkan. Analisis kesenjangan terhadap tingkat kemampuan teknologi informasi dilihat dari nilai kemampuan proses COBIT 5 kondisi saat ini dan nilai kemampuan

Dari hasil pengisian kuesioner pertanyaan pada framework DSS02, DSS03, MEA01, MEA02 dan EDM02

didapatkan Gap yang dapat dilihat pada gambar berikut :

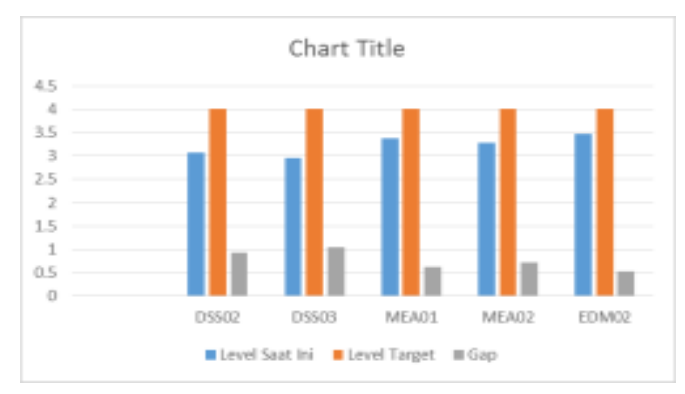

Gambar 12. Capability

Level Pencapaian level hasil kuisioner tersebut dapat disimpulkan bahwa tingka kapabilitas pelayanan pada Audit Pelayanan Sistem Rujukan Online Puskesmas saat ini adalah ratarata padalevel 3 yaitu Established Process berarti bahwa proses pelayanan pada Layanan Rujukan Online yang implementasikan belum sepenuhnya memiliki pelayanan yang baik.

\section{KESIMPULAN}

Dari hasil penelitian diperoleh kesimpulan, proses audit menggunakan domain DSS02, DSS03, MEA01, MEA02 dan EDM02 bahwa Audit Pelayanan Sistem Rujukan Online Puskesmas Menggunakan Framework COBIT 5 :
- Berdasarkan audit proses yang dilakukan menggunakan COBIT 5.0. tingkat kematangan yang dihasilkan saat ini untuk domain DSS02, DSS03, MEA01, MEA02 dan EDM02 rata - rata mencapai tingkat 3 (Established Process) berarti proses sudah pada tahap yang tetap diinstansi sudah pada tahap implementasi proses - proses terstandar, artinya sudah ada standar proses IT yang berlaku diseluruh lingkup organisasi dan dari segi tatanan strategis sudah pada tahap yang Stabil atau Established Proccess.

- Setiap proses subdomain pada kelima domain diberikan rekomendasi perbaikan yang nantinya bisa mempengaruhi tingkat kematangan saat ini untuk menuju tingkat perbaikan dan sampai pada kematangan yang ingin dicapai untuk meningkatkan proses kinerja instansi kearah yang lebih baik.

\section{DAFTAR PUSTAKA}

[1] Agoan, Tedi S, dkk. "Analisa Tingkat Kematangan Teknologi Informasi Pada Dinas Komunikasi dan Informatika Kota Manado Menggunakan Framework COBIT 5 Domain Evaluate, Deirect, Monitor (EDM) dan Delliver, Service, and Support (DSS)". E-Journal Teknik Informatika Vol. 10 No. 1Universitas Sam Ratulangi. (2017).

[2] Agoes, Sukrisno.Auditing Petunjuk Praktis Pemeriksaan Akuntan oleh Akuntan Publik. Edisi ke 4. Buku 1. Jakarta: Salemba Empat. (2014).

[3] Amrulloh, Arif, Gunawan Wibisono, and Agus Rakhmadi Mido. "Audit Tata Kelola Teknologi Informasi Pada Perguruan Tinggi Menggunakan Cobit 5 Fokus Proses Pelayanan." Jurnal Ilmiah KOMPUTASI 19.1 (2020): 115120.

[4] Cofriyanti, Ervi, Leni Novianti, and Dewi Irmawati Siregar. "Penilaian Tingkat Kematangan Sistem Informasi Manajemen Rumah Sakit yang Melayani BPJS dengan Framework COBIT 
(Studi Kasus: Rumah Sakit Swasta Kota Palembang)." Seminar Nasional Teknologi Informasi Komunikasi dan Industri. 2017.

[5] Cahyani, Ulfatisa, Ismiarta Aknuranda, and Andi Reza Perdanakusuma. "Evaluasi Layanan BPJSTK Mobile Dengan Menggunakan Domain Deliver, Service and Support Berdasarkan Framework COBIT 5 (Studi Kasus: BPJS Ketenagakerjaan Cabang Mataram)." Jurnal Pengembangan Teknologi Informasi dan Ilmu Komputer eISSN 2548 (2017): 964X.

[6] Fajrin, Rati Amanda, Murahartawaty Murahartawaty, and Soni Fajar S. Gumilang. "Perancangan Tata Kelola Teknologi Informasi di BAPAPSI Pemkab Bandung Menggunakan framework COBIT 5 Pada Domain EDM dan DSS." Journal of Information Systems Engineering and Business Intelligence 2.2 (2016): 74-80.

[7] Gondodiyoto, S. Dan Gautama, I. "Audit Sistem Informasi. Pendekatan konsep". McGraw Hill Companies, Inc.Jakarta. (2013)

[8] Indrajani. Database Design (Case Study All In One). Jakarta: PT Elex Media Komputindo. (2015)

[9] Kadir, Abdul. Pengenalan Sistem Informasi Edisi Revisi. Yogyakarta : Andi Offset. (2014).

[10] Krismiaji. "Sistem Informasi Akuntansi". Yogyakarta: Sekolah Tinggi Ilmu Manajemen YKPN. (2015)

[11] Pratama, Eka, Agus, I Putu. Teori dan Konsep Sistem Informasi Dan Implementasinya, Informatika , Bandung. (2014).

[12] Putri, Fiqih Zetrita, and Aldri Frinaldi. "Efektivitas Rujukan Online Bagi Pasien Rawat Jalan Dalam Program Jaminan Kesehatan Nasional (Jkn) Di Kota Solok." Jurnal Mahasiswa Ilmu Administrasi Publik 1.4 (2019): 28-38.

[13] Romney, Marshall B dan Paul John Steinbart. Sistem Informasi
Akuntansi. Jakarta : Salemba Empat. (2015)

[14] Pratama, Eka, Agus, I Putu. Teori dan Konsep Sistem Informasi Dan Implementasinya, Informatika , Bandung. (2014).

[15] Sasongko , N. Pengukuran Kinerja Teknologi Informasi Menggunakan Framework COBIT VERSI. 4.1, Ping Test Dan Caat Pada Pt.Bank X Tbk. Di Bandung. Seminar Nasional Aplikasi Teknologi Informasi. (2009)

[16] Setiawati, Marina Ery, and Rahmah Hida Nurrizka. "Evaluasi pelaksanaan system rujukan berjenjang dalam program jaminan kesehatan nasional." Jurnal Kebijakan Kesehatan Indonesia: JKKI. https://doi. org/10.22146/JKKI 43843 (2019).

[17] Tanuwijaya , H., \& Sarno , R. Comparation of CobiT Maturity Model and Structural Equation Model for Measuring the Alignment between University Academic Regulations and Information Technology Goals. IJCSNS International Journal of Computer Science and Network Security , 10. (2010)

[18] Vitrin, Irene Cindy Yeanne, Kraugusteeliana Kraugusteeliana and Anita Muliawati. "Rancangan Indikator Audit Sistem Informasi Kepuasan Pelanggan Menggunaka Framework COBIT 5 Domain DSS, ME dan, EDM (STUDI KASUS BPJS)." SEINASI-KESI 2.1 (2019): 119- 124.

[19] Yuliana, Khozin. Muhamad Zahrudin dan Tri Utari, Analisa Sistem Informasi Peminjaman Dan Pengembalian Buku Perpustakaan Pada SMA Nusantara 1 Tangerang, Jurnal SENSI Perguruan Tinggi Raharja, vol. 4, no.1, (201 